\title{
427. PHYSIOTHERAPY EFFECTS ON GAIT SPEED AND PAIN IN PATIENTS WITH KNEE OSTEOARTHRITIS ONE DAY AFTER APPLYING KINESIOTAPE
}

\author{
Klejda Tani ${ }^{1}$, Irena Kola ${ }^{1}$, Fregen Dhamaj ${ }^{1}$, Eriselda Qalliaj ${ }^{1}$, Kiri Zallari ${ }^{1}$ \\ ${ }^{1}$ Faculty of Technical Medical Sciences, University of Medicine, Tirana
}

Introduction: Knee osteoarthritis is a chronic degenerative disease, known as the most common cause of difficulty walking in older adults and subsequently is associated with slow walking, also one of the most main symptoms is a degenerative and mechanics type of pain. Pain is very noticeable while walking in rugged terrain, during ascent and descent of stairs, when changing from sitting to standing position as well as staying in one position for a long time. Many studies have shown that the strength of the quadriceps femoris muscle can affect gait, by improving or weakening it. Kinesiotape is a physiotherapeutic technique, which reduces pain and increases muscular strength by irritating the skin receptors

Purpose: The aims of this study was firstly to verify if the application of Kinesiotape (KT) on quadriceps femoris muscle increases gait speed in patients with knee osteoarthritis and secondly if applying Kinesiotape on quadriceps femoris muscle reduces pain while walking.

Method: 74 patients with primary knee osteoarthritis, aged 5073 years, participated in this study. Firstly we observed the change of gait speed, while walking for 10 meters at normal speed for each patient, before and one day after the application of Kinesiotape on quadriceps femoris muscle, with the help of the 10-meter walk test. Secondly we observed the change of pain, while walking for 10 meters at normal speed for each patient, before and one day after the application, with the help of Numerical Pain Rating Scale-NRS.

Results: Our results indicated that in the 10 meter wlk test (MWT) before KT application compared to 10MWT 1 day after $\mathrm{KT}$ application has no significant change, $P=0.23$. Also the results show that there is a significant reduction in pain level 1 day after KT application, compared with the level of pain before its application. The degree of pain reported prior to KT application compared to the reported pain level 1 day after KT application has a significant change, $\mathrm{P}<0.0001$.
Graphic 1: Comparison of gait speed in seconds before the application of KT (10MWT Before KT) and one day after the application of KT (10 MWT $1 \mathrm{D}$ After KT) on quadriceps femoris muscle.

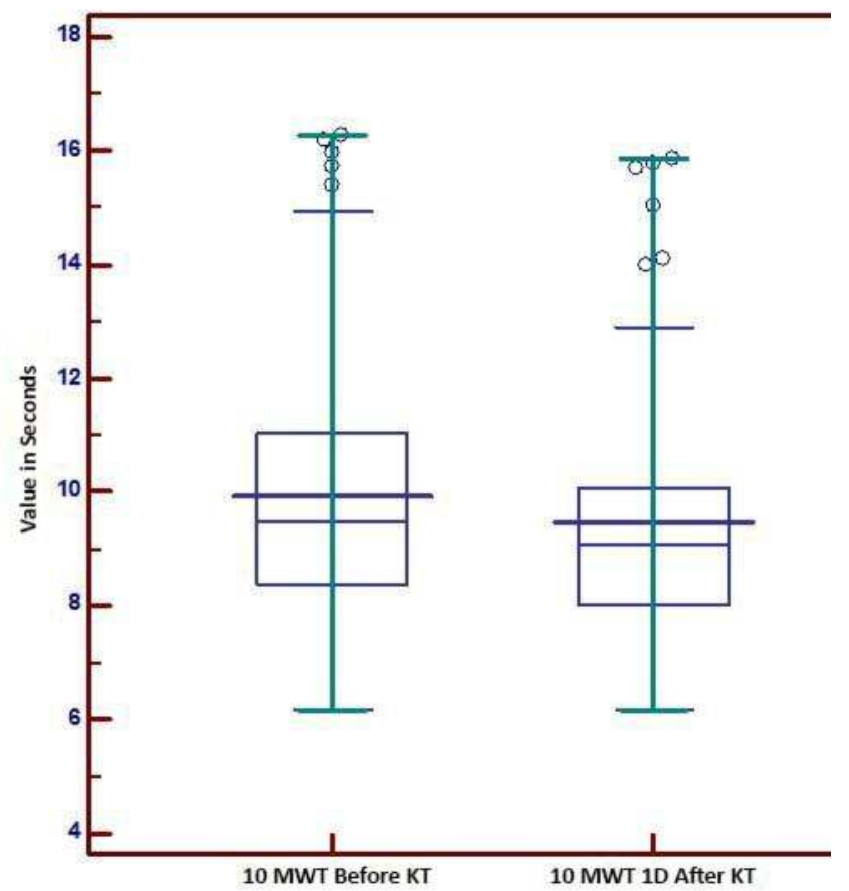

Graphic 3: Comparison of pain level results according to NRS prior to KT (NRS before KT) and one day after KT (NRS 1D after KT) application on quadriceps femoris muscle.

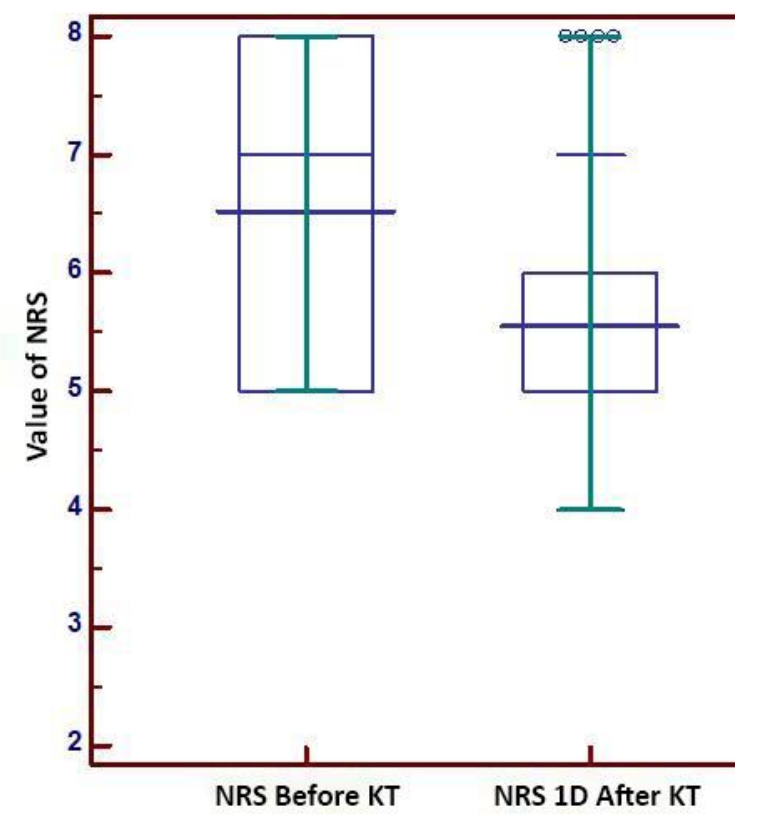

Conclusions: Our results indicated that there was a significant decrease of pain and increase of gait speed while walking for 10 meters. Kinesiotape can be used in patients with knee osteoarthritis, especially when changing walking stereotypes is a long term goal of the treatment.

Steultjens MP, Dekker J, van Baar ME, Oostendorp RA, Bijlsma JW. (2001). Muscle strength pain and disability patients with osteoarthritis. Clin Rehabil ;15:331-41.

2. Ayis S, Ebrahim S, Williams S, Juni P, Dieppe P. (2007). Determinants of reduced walking speed in people with musculoskeletal pain. J Rheumatol. ;34(9):1905-12.

3. Dekker J, Tola P, Aufdemkampe G, Winckers M. (1993). Negative affect, pain and disability in osteoarthritis patients: the mediating role of muscle weakness. Behav Res Ther; 31:203-6.

Vercelli S, Sartorio F, Foti C, Colletto L, Virton D, Ronconi G, et al (2012). Immediate effects

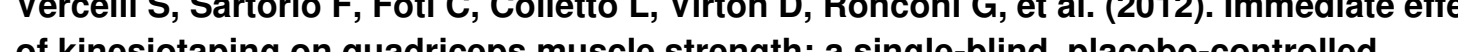
crossover

5. Lins CA, Neto FL, Amorim AB, Macedo LB, Brasileir JS. (2013). Kinesio Taping does not alter neuromuscular performance of femoral quadriceps or lower limb function in healthy subjects: randomized, blind, controlled, clinical trial. Man Ther.;18(1):41-5. 